\title{
nature
}

31 March 2005 Volume 434 Issue no 7033

\section{Drug safety on trial}

The current US system for checking the safety of drugs already on the market is toothless. Why isn't the government doing more to strengthen it?

A revealing notice appeared last month in the Federal Register, the US government compendium of agency rules and notices. The Food and Drug Administration (FDA) was reporting on compliance by pharmaceutical companies with its requests for studies of the clinical safety and efficacy of drugs already on the market. Of nearly 1,200 such studies committed to by drug firms but not completed, some $70 \%$ have yet to begin.

This is an alarming reflection of the state of the government's vigilance. Last year, the FDA belatedly faced up to research showing that the painkiller Vioxx, which it approved in 1999, markedly increases the risk of heart attacks and strokes. It has been estimated that more than 25,000 people died before Merck pulled the drug from the market in September (see pages 554 and 557). A better approach to assessing the safety of marketed drugs is badly needed.

Under the FDA's existing system, known as MedWatch, doctors voluntarily report suspected side-effects - but epidemiologists estimate that this captures only $10 \%$ of adverse events. The agency used to complement this with university-run studies, but this modest effort dried up in the 1990s when it was forced to devote more resources to speeding up drug approvals.

The upshot is that the FDA depends on companies for post-market safety studies but has no legal authority to force firms to do them. The results are sobering. For instance, after 16 years of use in tens of millions of people, it is still not known whether selective serotonin reuptake inhibitors, the blockbuster antidepressants, cause an increase in suicide attempts in some adults. The FDA warned last year of such a risk in young people, but the question still hasn't been adequately explored in adults. Nor will it be if the current system prevails.

Lack of information is not the problem. After a drug comes into use, gigabytes of epidemiological data become available from governments and healthcare organizations. Nor is it a matter of sorting through the 10,000-odd prescription drugs to find one with dangerous side-effects: the most likely culprits are already well known.

What is lacking is both the money and the mandate. The United States needs a government body that can not only determine what drug safety studies are needed, but demand that they are done. It must also have the authority to dictate - rather than negotiate with drugmakers, as the FDA currently does - that beefed-up warning labels are used when evidence of new risks emerges. About $\$ 300,000$ annually would pay for a high-quality pharmaco-epidemiological study. Surely the richest country in the world can find the funds for that.

It can, but will it? Congress is unlikely to implement such a change. The Republicans control Congress and the White House, and are loath to alienate an industry that has given them twice as much as it has given the Democrats in political contributions over the past decade.

Tens of thousands of people have almost certainly died because of Vioxx. Observers are left to wonder if it will take an even bigger tragedy to force the US government to do the right thing on drug safety.

\section{A state of ignorance}

\section{Severe brain damage attracts little research attention, yet science could help inform the decisions of doctors and families.}

$\mathrm{T}$ he bitter wrangle over the fate of Terri Schiavo, the severely brain-damaged woman at the centre of a political and emotional storm in the United States, is highly distressing. Her husband has fought to allow her to die; her parents have argued that she might yet recover. As Nature went to press, Schiavo's parents seemed to have exhausted their legal options, and their daughter has had her feeding tube removed.

It is not our intention to pass judgment on Schiavo's fate. But for patients with related conditions, and their families and doctors, science may have a role to play that is not being fully explored.

In the case of Schiavo, whose brain was temporarily starved of oxygen 15 years ago, medical opinion seems clear. Neurologists say that she is in a persistent vegetative state and is unable to respond to instructions. Her chances of recovery are close to zero.

But when the prognosis is less certain, research may be able to help. Some severely brain-damaged patients are described as being in a minimally conscious state. These patients are occasionally able to respond to commands and are thought to have a slightly better chance of some recovery.

In a study published last month (N. D. Schiff et al. Neurology 64, 514-523; 2005), researchers probed the brains of two such patients using functional magnetic resonance imaging while relatives read them personal stories. The researchers found activity in language networks that was similar to that of healthy individuals. Other scans have shown the brain regions that are physically damaged, but not which circuits can respond to stimuli.

The results are only preliminary: it is not clear, for example, what the patients actually experienced. But researchers could potentially distinguish a persistent vegetative state from a minimally conscious state, or even identify conditions in between. They might even find signature patterns that can help predict the likelihood of recovery.

Perhaps the biggest obstacle is the perception in the medical and research community that severely brain-damaged patients are a lost cause. This is reflected in the number of research groups scanning the brains of such patients; they can be counted on one hand.

Some researchers have to battle for permission to work with braindamaged patients. Patients who cannot consent to research must clearly be safeguarded. But the situation could be simplified through living wills, which allow people to specify the treatment they want if they become incapacitated. These could include requests about participation in research, as some already do about organ donation.

The ethical and medical issues involved in these cases will always be excruciatingly difficult, even when the diagnoses are as clear-cut as Schiavo's. An increased motivation to tackle research in this area won't make the problems go away, but it could help to inform the difficult decisions that families and doctors are forced to take. 